\title{
DIALOGANDO COM ESTUDANTES: AS PREFERÊNCIAS DAS DANÇAS NO MEIO UNIVERSITÁRIO
}

Beatriz Ariane Soares'; Luiz Henrique Batista Monteiro²; Claudia Mara Niquini ${ }^{3}$, Priscila Lopes ${ }^{4}$; Juliana Nogueira Pontes Nobre ${ }^{5}$

1-Educadora Física, Universidade Federal dos Vales do Jequitinhonha e Mucuri (UFVJM). Diamantina, Minas Gerais, Brasil. (junobre2007@yahoo.com.br)

2-Enfermeiro. Mestrando do Programa de Pós-Graduação em Saúde, Sociedade e Ambiente, Universidade Federal dos Vales do Jequitinhonha e Mucuri (UFVJM). Diamantina, Minas Gerais, Brasil.

3-4-Educadora Física. Departamento de Educação Física, Faculdade de Ciências Biológicas e da Saúde, Universidade Federal dos Vales do Jequitinhonha e Mucuri. Diamantina, Minas Gerais, Brasil.

5- Educadora Física. Mestre em Saúde, Soc. e Ambiente pela Universidade Federal dos Vales do Jequitinhonha e Mucuri (UFVJM). Diamantina, Minas Gerais, Brasil.

Recebido em: 06/04/2019 - Aprovado em: 10/06/2019 - Publicado em: 30/06/2019 DOI: 10.18677/EnciBio_2019A167

\begin{abstract}
RESUMO
As danças estão atreladas a história do homem, uma vez que dançamos para nos comunicar, contar e recontar histórias, para expressar os sentimentos presentes nas vidas humanas, nos diversos cantos do mundo. O objetivo do estudo foi verificar as preferências de estilos músicais para dançar de estudantes de uma universidade pública de uma cidade do interior de Minas Gerais e compreender as possíveis relações entre as preferências dos estudantes e as interferências/influências da indústria cultural. Tratou-se de um estudo exploratório, transversal, contemplando 106 estudantes de graduação. Os resultados apontam que o Forró, Sertanejo e Funk foram os prediletos entre os entrevistados. Entende-se que os estilos preferidos pelos universitários representam em parte àqueles mais presentes nos meios de comunicação social, aos quais se atribui valores e significados transmitidos pelas letras das músicas que os jovens dançam, atribuem valores como o tratamento à mulher, os gestos de conotação sexual e a massificação dos corpos. Ressaltamos os interesses comerciais de grupos específicos, detentores de veículos de comunicação que atendem ao mercado de consumo de produtos (impostos), contribuindo para a massificação da cultura. Desta forma as danças midiáticas, distribuídas pelos meios de comunicação, seriam danças dedicadas ao mercado e não a criação artística.
\end{abstract}

PALAVRAS-CHAVE: Danças, Mídia, Preferência. 


\title{
DIALOGING WITH STUDENTS: THE PREFERENCES OF DANCES IN THE UNIVERSITY ENVIRONMENT
}

\begin{abstract}
Dances are tied to the history of man as we dance to communicate, tell and recount stories, to express the feelings present in human lives, in the various corners of the world. The purpose of the study was to verify the preferences of music styles for dancing of students from a public university of a city in the interior of Minas Gerais and to understand the possible relationships between students' preferences and the influences / influences of the cultural industry. It was an exploratory, cross-sectional study, involving 106 undergraduate students. The results indicate that Forró, Sertanejo and Funk were the favorites among the interviewees. It is understood that the styles preferred by university students represent in part those most present in the media, which are attributed values and meanings transmitted by the lyrics of the songs that young people dance, attribute values such as the treatment of women, gestures of connotation and the massification of bodies. We emphasize the commercial interests of specific groups, holders of communication vehicles that serve the product consumption market (taxes), contributing to the massification of culture. In this way the media dances, distributed by the media, would be dances dedicated to the market and not the artistic creation.
\end{abstract}

KEYWORDS: Dances, Media, Preference.

\section{INTRODUÇÃO}

As manifestações culturais se encontram presentes na história da humanidade desde períodos remotos, retratadas nas pituras rupestres pelos gestos que remetem à dança (FARO, 1998). Há vestígios na literatura de que a base da dança tem um cunho religioso e, à medida que esta se aparta desta origem, ganha novas tendências (FARO, 1998; BRASILEIRO, 2010).

Mas, diante de tantas manifestações corporais, ao se pensar no homem com suas danças, pergunta-se: para quê os homens dançam? Brasileiro (2010) cita que o homem dança para se comunicar, contar e recontar histórias, para expressar os sentimentos presentes nas vidas humanas, nos diversos cantos do mundo, nas ruas, nas casas noturnas, nos espetáculos, nas escolas, nos estúdios e nas universidades. Neste prisma, a dança é também um veículo de comunicação dos corpos ao rítmo do som, das batidas das músicas aos quais à comunicação entre música e dança se fazem tão intensas que raramente é possível dissociá-las uma da outra ao pensar em dançar (VIEIRA, AVELINO, 2014; RODRIGUES; SOUZA, 2017).

No sentido de compreender a preferência por diferentes estilos musicais para dançar como manifestação cultural se propõe pensar a cultura à luz de conceitos trazidos por alguns estudiosos da literatura, dentre eles Bourdieu (1987). O autor se dedica a entender os mecanismos sociais que dão origem à criação artística e que explicam os diferentes modos do consumo na cultura.

Pretende-se pensar no consumo da cultura nas classes sociais, no entendimento do conceito de "indústria cultural", termo criado por Adorno e Max Horkheimer a fim de explicar a relação existente entre a lógica de produtividade do capitalismo e suas aplicações na cultura (ADORNO, 1985; CUCHE, 1999). Desta forma, a transformação de bens culturais em mercadorias conceitua de forma sintética o termo "indústria cultural". Somado a este entendimento, é importante reconhcer a forte influência da indústria e da massificação da cultura sobre o gosto e 
as preferências individuais (FARIAS, COSTA, 2015), uma vez que a indútria cultural precisa, necessariamente, de um mercado de consumo (GUARATO, 2016).

Com o foco nas transformações que permeiam o universo da dança é preciso considerar o fato contemporâneo da presença dos meios de comunicação e mídias na divulgação das manifestações corporais, que facilitam aprendizados, disseminação dos passos, resignificação no qual com um clique se consegue aprender passos de forró, funk ou outros estilos. Tomazzoni (2015) acredita que a dança na mídia reflete um constante atravessamento de suportes, linguagens de produção, formas de consumo que se torna impossível separar os entendimentos em razão da rápida veiculação por vários segmentos. Cita-se, a saber, os programas de televisão que difundem a dança em aberturas e cenas de telenovelas, os videoclipes dos diversos gêneros (hip hop, sertanejo, pagode, pop music, funk, etc.) e artistas, formando um circuito cultural com singularidades políticas dos corpos que dançam que envolvem produção, consumo e representações.

Tomazzoni (2015) concorda com Tortola e Lara (2011) no que tange a existência de um mundo onde as relações estabelecidas são amparadas na "liberdade corporal", representado também pelos espaços de mercadorização de bens culturais, onde os sujeitos interagem com interesse social, em que as danças da moda são disseminadas pelos meios de comunicação e que passam a se configurar como mercadoria. Os diferentes atores sociais, entendidos como os praticantes adeptos, dançam funk, sertanejo, samba, forró, punk, pop rock entre outros estilos mais tocados, ou "da moda".

Logo, os estudos que relacionam os estilos de dança praticados e preferidos pelos estudantes se fazem necessário para entender como se configura este ator inserido neste contexto. Com o intuito de pesquisar a preferência de dança de estudantes de determinada universidade pública federal do interior do Estado de Minas Gerais, considerando as múltiplas interferêcias/influências descritas às quais cita-se o mercado, o consumo, o corpo inserido neste universo, pretende-se entender as possíveis relações destas com as preferências de danças dos estudantes.

Sendo assim, esta pesquisa teve como objetivo investigar a preferência de estudantes de uma universidade pública federal situada no interior do Estado de Minas Gerais, por determinados estilos musicais para dançar. Pretende-se com isso, compreender as possíveis relações entre as preferências dos estudantes e a múltiplas interferências/influências da indústria cultural.

\section{MATERIAL E MÉTODOS}

Este estudo, de caráter transversal, exploratório, aprovado pelo Comitê de Ética em Pesquisa da universidade Federal dos Vales do Jequitinhonha e Mucuri (parecer 2.953.810), contempla uma amostra de conveniência de 106 estudantes de graduação de cursos presenciais da referida instituição.

A coleta foi realizada entre os meses de Outubro e Novembro de 2018. A pesquisadora responsável pela coleta, previamente autorizada pelo professor da aula, instruiu os estudantes sobre a pesquisa e entregou os questionários, recolhendo após um período de 15 minutos com os dados coletados. Foram considerados critérios de inclusão: ser estudante e formando em graduação na UFVJM- campus JK.

Utilizou-se um questionário especialmente elaborado para esta pesquisa, amparado na literatura (PIMENTEL et al., 2005, TORTOLA; LARA, 2011), uma vez que não há disponível na literatura este instrumento validado. Neste recorte, 
apresenta-se os resultados referente à três perguntas geradoras, quais sejam: "Você gosta de dançar?"; "Marque com um " $x$ " o quanto você gosta de dançar conforme cada gênero musical abaixo"; "Onde você costuma dançar?".

Os estilos musicais mencionados entre as possibilidades de respostas foram amparados no estudo de Pimentel et al. (2005). As respostas objetivas foram amparadas na Escala de Preferência Musical para a descoberta do grau de preferência, baseado na escala Likert no qual as opções de marcações vão de detesto a gosto muito.

Os dados foram digitados e analisados no programa Statistical Package for the Social Sciences (SPSS), versão 23.0 para análise descritiva das variáveis. Para as análises consideraram-se os valores absolutos, frequência e intervalo de confiança 95\% (IC=95\%).

\section{RESULTADOS E DISCUSSÃO}

Participaram deste estudo, 106 estudantes dos quais a maioria é do sexo feminino (76,4\%). Essa pesquisa contemplou alunos graduandos da área da saúde. da educação e das exatas. Na caracterização dos universitários, nota-se que a faixa etária predominante é de alunos jovens com idade entre 22 e 25 anos. Mais da metade são naturais de outras localidades (55\%), enquanto menos da metade são de Diamantina e microrregião $(44,6 \%)$ e a maioria reside na cidade por um período de até cinco anos. A tabela 1 apresenta os dados relatados.

TABELA 1: Caracterização sociodemográfica dos universitários participantes do estudo $(n=106)$.

\begin{tabular}{|c|c|}
\hline Variáveis & $\mathbf{N}(\%)$ \\
\hline \multicolumn{2}{|l|}{ Sexo } \\
\hline Masculino & $25(23,6)$ \\
\hline Feminino & $81(76,4)$ \\
\hline \multicolumn{2}{|l|}{ Curso } \\
\hline Medicina & $33(31,1)$ \\
\hline Educação Física & $23(21,7)$ \\
\hline Pedagogia & $21(19,8)$ \\
\hline Ciências Biológicas & $15(14,2)$ \\
\hline Agronomia & $7(6,6)$ \\
\hline Fisioterapia & $7(6,6)$ \\
\hline \multicolumn{2}{|l|}{ Idade, em anos* } \\
\hline 17 a 21 & $12(13,5)$ \\
\hline 22 a 25 & $52(58,4)$ \\
\hline 26 a 30 & $19(21,3)$ \\
\hline$<30$ & $6(6,7)$ \\
\hline \multicolumn{2}{|l|}{ Naturalidade $^{\star}$} \\
\hline Diamantina & $32(34,8)$ \\
\hline Microrregião de Diamantina & $9(9,8)$ \\
\hline Outras cidades & $51(55,4)$ \\
\hline \multicolumn{2}{|l|}{ Residência* } \\
\hline Diamantina & $90(86,5)$ \\
\hline Microrregião de Diamantina & $14(13,5)$ \\
\hline \multicolumn{2}{|l|}{ Reside em Diamantina* } \\
\hline Menos de dois anos & $3(3,1)$ \\
\hline Entre 2 a 4 anos & $57(59,4)$ \\
\hline$<5$ anos & $36(37,5)$ \\
\hline
\end{tabular}

*Número de respostas válidas para a questão.

A maior quantidade de estudantes serem do sexo feminino corrobora com o 
último censo de educação superior feito pelo Instituto Nacional de Estudos e Pesquisas Educacionais Anísio Teixeira (INEP), que versa sobre a inserção da mulher no ensino superior, com dados que revelam representatividade feminina de quase $60 \%$ entre os alunos matriculados no ano de 2016 . Importante ressaltar os desafios das universidades para a presença feminina, em razão dos estereótipos moldados socialmente que entendem a pré-existência de empregos, carreiras e também posições que competem apenas ao mundo masculino (MELO; BARRETO, 2014). A preferência de estilos musicais para dançar dos estudantes está descrita e agrupada na tabela 2.

TABELA 2: Preferência musical dos universitários da Universidade Federal dos Vales do Jequitinhonha e Mucuri do estado de Minas Gerais

\begin{tabular}{|c|c|}
\hline Variáveis & $\mathbf{N}(\%)$ \\
\hline \multicolumn{2}{|l|}{ Gosta de dançar } \\
\hline Gosto muito/gosto/gosto pouco & $102(96,2)$ \\
\hline Não gosto/ detesto & $4(3,8)$ \\
\hline \multicolumn{2}{|l|}{ Gosta de funk } \\
\hline Gosto muito/gosto/gosto pouco & $84(79,2)$ \\
\hline Não gosto/ detesto & $22(20,8)$ \\
\hline \multicolumn{2}{|l|}{ Gosta de pagode } \\
\hline Gosto muito/gosto/gosto pouco & $74(69,8)$ \\
\hline Não gosto/ detesto & $32(30,2)$ \\
\hline \multicolumn{2}{|l|}{ Gosta de forro } \\
\hline Gosto muito/gosto/gosto pouco & $98(92,5)$ \\
\hline Não gosto/ detesto & $8(7,5)$ \\
\hline \multicolumn{2}{|l|}{ Gosta de samba } \\
\hline Gosto muito/gosto/gosto pouco & $80(75,5)$ \\
\hline Não gosto/ detesto & $26(24,5)$ \\
\hline \multicolumn{2}{|l|}{ Gosta de sertanejo } \\
\hline Gosto muito/gosto/gosto pouco & $91(85,8)$ \\
\hline Não gosto/ detesto & $15(14,2)$ \\
\hline \multicolumn{2}{|l|}{ Gosta de música clássica } \\
\hline Gosto muito/gosto/gosto pouco & $57(53,8)$ \\
\hline Não gosto/ detesto & $49(46,2)$ \\
\hline \multicolumn{2}{|l|}{ Gosta de hip-hop } \\
\hline Gosto muito/gosto/gosto pouco & $57(53,8)$ \\
\hline Não gosto/ detesto & $49(46,2)$ \\
\hline \multicolumn{2}{|l|}{ Gosta de pop music ${ }^{*}$} \\
\hline Gosto muito/gosto/gosto pouco & $77(73,3)$ \\
\hline Não gosto/ detesto & $28(26,7)$ \\
\hline \multicolumn{2}{|l|}{ Gosta de punk heard core* } \\
\hline Gosto muito/gosto/gosto pouco & $31(29,8)$ \\
\hline Não gosto/ detesto & $73(70,2)$ \\
\hline \multicolumn{2}{|l|}{ Gosta de heavy metal ${ }^{*}$} \\
\hline Gosto muito/gosto/gosto pouco & $30(28,6)$ \\
\hline Não gosto/ detesto & $75(71,4)$ \\
\hline \multicolumn{2}{|l|}{ Gosta de música religiosa* } \\
\hline Gosto muito/gosto/gosto pouco & $66(62,6)$ \\
\hline Não gosto/ detesto & $39(37,1)$ \\
\hline \multicolumn{2}{|l|}{ Gosta de reggae* } \\
\hline Gosto muito/gosto/gosto pouco & $81(77,1)$ \\
\hline Não gosto/detesto & $24(22,9)$ \\
\hline
\end{tabular}

* Número de respostas válidas para a questão.

Pelo exposto, observou-se que o gosto pela dança é manifestado por quase todos os entrevistados (apenas 3.8\% não gostam ou detestam dançar). Desta forma, 
entende-se que a dança, presente desde o surgimento da humanidade, ainda se faz presente na cultura enquanto veículo de comunicação (FARO, 1998, BRASILEIRO, 2010).

Levando-se em consideração que a maior parte dos sujeitos pesquisados são mulheres, entende-se que o gosto pela dança seja também influenciado pelo processo histórico da cultura do divertimento descrito por Rodrigues e Souza (2017), que atribuem figuras e funções associadas à tradições masculinas, como elaboração de letras e execução de músicas, e as funções associadas ao universo feminino, como a dança.

A preferência de estilo de música para dançar entre os entrevistados, foi, respectivamente, forró, funk, sertanejo e pagode com maior aprovação e predileção. Outros estilos (música religiosa, punk, hip hop) aparecem com menor preferência entre os estudantes. Para melhor visibilidade e esclarecimento dos resultados, a preferência de estilos musicais para dançar dos participantes estão representados no gráfico 1.

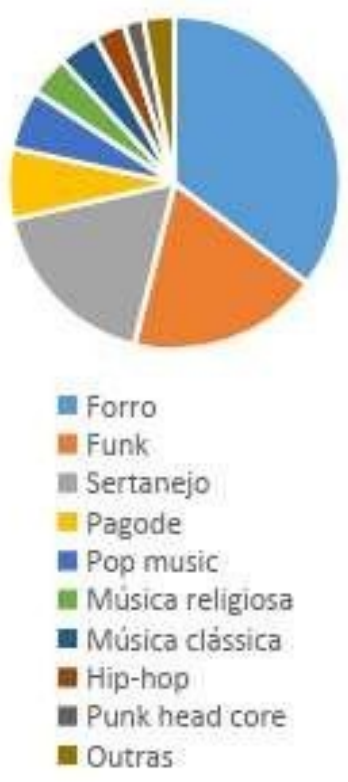

GRÁFICO 1: Preferência de Dança dos Universitários

Forró (34.3\%); Funk (18.1\%); Sertanejo (17.1\%); Pagode (6.7\%); Pop music (5.7\%); Religiosa (3.8); Música Clássica (3.8\%);. Hip-hop (2.95); Punk Head Core (1.9\%) Outros (2.9\%).

No intuito de compreender as possíveis causas para que tais gêneros obtivessem lugar de destaque no cotidiano dos discentes, buscou-se considerar as características dos três estilos mais citados (forró, funk, sertanejo). Primeiramente, considerando o caráter afetivo presente tanto no forró quanto no sertanejo oportuniza-se uma possível correlação entre a predileção dos estudantes para com estes estilos.

No que se refere ao forró, oriundo do período pós-segunda guerra mundial nas festas promovidas por militares estrangeiros presentes no litoral brasileiro, este estilo musical tornou-se um dos símbolos da cultura nordestina. Na década de 1990, emergiu o forró eletrônico cujas tendências mercadológicas se tornam evidentes para atrair novos adeptos (BRILHANTE et al., 2017; BRILHANTE et al., 2018). 
Paes (2017) resume as principais temáticas deste gênero ao afirmar que "no forró, revivem-se os modos de amar, os afetos, se fala de saudade, da vida no campo e de seus códigos, da conexão com a natureza, dos desdobramentos das relações de poder no campo e na cidade, falam-se das crenças e da fé" (p.171).

Percebem-se então, pontos favoráveis para que os entrevistados se identificassem com o estilo, como a alusão criada quase que instantaneamente entre o ritmo e dança. Essa ideia de contato entre corpos abre caminhos também para a intimidade, contato corporal (CUNHA; PARAISO, 2015; NUNES; ZAMBOM, 2018), é possível contato entre aqueles que dançam (SCHLÖSSER et al. 2016). Este fato pode também ser associado ao ritmo e a conotação sexual presente nas letras das músicas, sejam na versão mais tradicional, onde a sexualidade aparece de forma mais sutil, ou no forró eletrônico da atualidade, caracterizado por uma temática sexual explícita.

Outro fator que pode se associar a ampla preferência por este estilo, é o de que muitos dos entrevistados passaram pelo processo de deslocamento e mudança do lugar em que moravam (55,4\% dos pesquisados), para a cidade na qual se localiza a Universidade, caracterizando assim uma espécie de êxodo, que é também uma temática comum nas letras de músicas do forró e que possa ser um elemento comum ao estudante.

A preferência do sertanejo pelos entrevistados desta pesquisa pode ser compreendida através do ambiente acadêmico em que vivem, visto que o histórico do próprio estilo musical, uma vez que a música sertaneja universitária (com incorporação de instrumentos como baixo, guitarra e percussão), sendo uma variação ou uma versão urbanizada da música caipira, foi disseminada por meio da migração de jovens universitários do interior que levaram a música sertaneja raiz para os campi e repúblicas. Schlösser et al. (2016) afirmam que os percussores deste estilo ofereciam cortesia aos universitários para prestigiar seus shows, o que trouxe o termo "Universitário" A música propicia valores, pensamentos e práticas compartilhadas pelos grupos o que facilita a interação das pessoas.

Fraga e Souza (2016) afirmam que a música caipira passou a ser sertaneja quando passou a ser tocada nas rádios, consumida como produto cultural, no qual, existia um temor de que ouvintes das rádios identificassem as duplas (sertanejas) como caipiras e se desinteressassem pelas músicas antes de ouví-las pelo preconceito à figura campestre. Neste momento percebeu-se que a música deixou de ser a arte da alma do povo para se transformar numa indústria, consumida como um produto cultural, atribuindo a denominação de sertaneja e sofrendo transformações para se adequar aos padrões comerciais (LEITÃO, 2017).

O funk, por sua vez, apresenta uma diversidade e também multiculturalidade capaz de encantar aqueles que se identificam com o gênero. Isto por que o funk é capaz de acolher uma diversidade de formas de conteúdos de uma variedade de segmentos musicais, o que permite que o indivíduo se identifique com este estilo, devido à presença de elementos culturais que já são de sua preferência e contato (VIANA, 2016). Fruto do hibridismo do hip-hop, cuja origem é americana, o funk tem suas origens relacionadas às questões sociais oriundas do povo negro das favelas, com ampla disseminação graças à indústria cultural, conforme elucida a autora.

A literatura traz o entendimento de um fenômeno de alienação cultural, onde os indivíduos agem inconscientemente, reproduzindo os produtos do sistema, em que são passivos diante dos fenômenos de massificação. Portanto, são convencidos a consumir, e o gosto seria apenas mais um produto desta alienação maior. Desta forma, quando tentam se libertar dessa passividade, escolhe de outra forma aquilo 
que foram inclinados (convencidos) a escolher (FARIAS; COSTA, 2015).

A luz desse pensamento, a cultura do funk precisa ser problematizada, uma vez que é conhecida a massificação desta manifestação também pela indústria cultural. Reconhece-se a importância deste estilo por meio da trajetória histórica, do significado de resistência do povo das favelas, negros, marginalizados e discriminados (SILVA, 2016), mas é preciso contextualizar os conceitos trazidos nas letras, referentes à conotação sexual, tratamento da mulher, cultura do estupro com o termo "violência ostentação" (BRILHANTE et al., 2019), incitação à violência descrita nos bailes com características peculiares (CYMROT, 2012) que, como também acontece em outros estilos como no forró (BRILHANTE et al., 2017, BRILHANTE et al., 2018), o sertanejo, em outros contextos e não apenas neste, representam ainda valores e práticas das pessoas.

A vida é um contínuo de atos, consoante com o pensamento de Brasileiro (2010) de que o sujeito, a experiência social e a cultura se constituem de interação social e, portanto, não são fragmentados. Neste caso, a dança, como outros fenômenos é produto destas interações. Este pensamento precisa ser problematizado, visto a existência do termo já discutido "indústria cultural" que designa tanto uma fusão entre a arte popular (conhecida como inferior) e erudita (dita superior) e o comércio de ambas como produto do capitalismo.

E possível entender que os estilos preferidos pelos universitários representam em parte, àqueles mais presentes nos meios de comunicação social. É importante ressaltar os interesses comerciais de grupos específicos, detentores de veículos de comunicação que atendem ao mercado de consumo de produtos (impostos), entendido como a sociedade, contribuindo para a massificação da cultura (GUARATO, 2016). Este autor afirma ainda que as danças midiáticas, distribuídas pelos meios de comunicação, seriam danças dedicadas ao mercado e não a criação artística e lidam com uma forma de funcionamento que se pautam na mera reprodução que não se contemplam os processos de reflexão e autonomia dos sujeitos que as praticam.

Os locais de costume de dançar relatados pelos entrevistados estão apresentados na tabela 3 .

TABELA 3: Locais onde os entrevistados costumam dançar.

\begin{tabular}{|cc}
\hline Variáveis & $\mathbf{N}(\%)$ \\
\hline Em casa* & \\
Não & $70(66,7)$ \\
Sim & $35(33,3)$ \\
Academia* & \\
Não & $95(90,3)$ \\
Sim & $10(9,5)$ \\
Bares $^{*}$ & \\
Não & $100(95,2)$ \\
Sim & $5(4,8)$ \\
Festas $^{*}$ & $30(28,6)$ \\
Não & $75(71,4)$ \\
\hline Sim &
\end{tabular}

* Número de respostas válidas para a questão.

Os universitários afirmaram ser em festas os locais onde mais constumam dançar. Compreende-se que os movimentos de festas universitárias façam parte do público Universitário. A proposta, neste contexto, é uma reflexão sobre a relação do 
ambiente/espaço com os estilos de maior preferência para dançar. Tortola e Lara (2011) ao estudarem os hábitos de dança em casas noturnas afirmam que, os espaços de dança se submetem às músicas de sucesso em que os objetos se portam como sujeitos, consoante com o pensamento de Adorno (1999) ao ilustrar o caráter manipulador do mercado que torna os sujeitos meros consumidores. As críticas a este pensamento se fazem no entendimento de que os sujeitos são levados a escolher algo, fruto de um movimento cuja influencia e a manipulação é alienante, no sentido de que alimentam o mercado de consumo.

É importante destacar o espaço de mercadorização de bens culturais onde as danças passam a se configurar como mercadoria atrelada à moda e aos artistas da mídia, em que os diferentes atores sociais (que dançam funk, sertanejo samba, dentre outros), dançam as músicas mais tocadas, que, por meio da sua letra, instigam comportamentos, ideias onde o sujeito se torna passivo à indústria da diversão (TORTOLA; LARA, 2011; TOMAZZONI, 2015; GUARATO, 2016).

Desta forma os grandes meios de comunicação passam a funcionar como colaboradores essenciais para uma cultura massificada que alcança diferentes lugares (ADORNO, 1985; TORTOLA; LARA, 2011; FARIAS; COSTA, 2015; GUARATO, 2016) que legitimam na sociedade aquilo que é produzido, passando assim a se auto definir como indústrias produtoras de mercadorias de valor social que influencia a construção das identidades (BRILHANTE et al., 2017, BRILHANTE et al., 2018).

Logo, a dança, ainda que seja praticada desde os primórdios nos períodos dos antepassados (BRASILEIRO, 2010) em diferentes contextos, permeia este universo de massificação cultural pelo qual o objetivo é de longe se pensar na arte, mas no mercado.

\section{CONCLUSÃo}

O estudo teve como proposta investigar a preferência de estudantes de uma Universidade Pública Federal situada no interior de Minas Gerais, por determinados estilos para dançar. Neste sentido, os estilos musicais de maior preferência relatados pelos estudantes foram Funk, Forró, Sertanejo. Ao refletir as possíveis relações das preferências com o consumo e a indústria cultural, entende-se que a dança é um veículo de comunicação dos corpos inseridos na cultura e influenciada pelos mecanismos sociais, pela indústria cultural e massificação da cultura.

Sugere-se que as manifestações preferidas sejam um produto consumido nos distintos espaços em que as danças acontecem, ao atender as "preferências" dos entrevistados em que escolhe-se as opções ditadas que poderiam refletir as mais tocadas pelo mercado, na concepção de produto a ser consumido.

\section{AGRADECIMENTOS}

Agradecemos ao GEPG (Grupo de Estudos de Práticas em Ginástica) da UFVJM.

\section{REFERÊNCIAS}

ADORNO, T. W.; HORKHEIMER, M. Dialética do esclarecimento. Rio de Janeiro: Zahar, p. 110-112, 1985.

ADORNO, T. W. O Fetichismo na música e a regressão da audição. In: Textos escolhidos. São Paulo: Nova Cultura, p. 65-69, 1999. 
BOURDIEU, P. Los tres estados del capital cultural. Sociológica, v. 2, n. 5, p. 11$17,1987$.

BRASILEIRO, L. T. A dança é uma manifestação artística que tem presença marcante na cultura popular brasileira. Pro-Posições, v. 21, n. 3, p. 135-153, 2010. Disponível em: <http://www.scielo.br/pdf/pp/v21n3/v21n3a09.pdf>. Acesso em: 5 fev. 2019.

BRILHANTE, A. V. M.; SILVA, J. G.; VIEIRA, L. J. E. S.; BARROS, N. F.; CATRIB, A. M. F. Construção do estereótipo do "macho nordestino" nas letras de forró no Nordeste brasileiro. Interface-Comunicação, Saúde, Educação, v. 22, n. 64, p. 13-28. 2017. Disponível em: <http://dx.doi.org/10.1590/1807-57622016.0286. doi: 10.1590/1807-57622016.0286.

BRILHANTE, A. V. M.; NATIONS, M. K.; CATRIB, A. M. F. "Taca cachaça que ela libera": violência de gênero nas letras e festas de forró no Nordeste do Brasil. Cadernos de Saúde Pública, v. 34, v. 3, p. 1-12, 2018. Disponível em: <http://dx.doi.org/10.1590/0102-311X00009317. doi: 10.1590/0102-311X00009317.

BRILHANTE, A. V. M.; GIAXA, R. R. B.; BRANCO, J. G. O.; VIEIRA, L. J. E. S. Cultura do estupro e violência ostentação: uma análise a partir da artefactualidade do funk. Interface-Comunicação, Saúde, Educação, v. 23, p. 1-13, 2019. Disponível em: https://doi.org/10.1590/Interface.170621. doi: 10.1590/Interface.170621.

CUCHE, D. A noção de cultura nas ciências sociais. Tradução de RIBEIRO. V. Bauru: EDUSC, p. 11-15, 1999. Disponível em: < https://we.riseup.net/assets/404112/Dennys+Cuche+A+No\%C3\%A7\%C3\%A3o+de+ Cultura+ nas+Ci\%C3\%AAncias+Sociais.pdf. > Acesso em: 10 jan. 2019.

CUNHA, M. M. S.; PARAISO, M. A. Biopolítica de endereçamentos de gênero no currículo do forró eletrônico. Revista Linhas, v. 16, n. 30, p. 180-213, 2015. Disponível em: http:/dx.doi.org/10.5965/1984723816302015180. doi: $10.5965 / 1984723816302015180$.

CYMROT, D. Ascensão e declínio dos bailes de corredor: O aspecto lúdico da violência e a seletividade da repressão policial. Sistema Penal \& Violência, v. 4, n. 2, p. 169-179. $2012 . \quad$ Disponível em: http://revistaseletronicas.pucrs.br/ojs/index.php/sistemapenaleviolencia/article/view/1 2364/8810>. Acesso em: 9 fev. 2019.

FARIAS, T. R. P; COSTA, J. H. Ensaio sobre o 'gosto' em Theodor W. Adorno e Pierre Bourdieu. Acta Scientiarum. Human and Social Sciences. Maringá, v. 37, n. 1, p. 93-101, jan./jun. 2015. Disponível em: http://dx.doi.org/Doi: 10.4025/actascihumansoc.v37i1.26196. doi: 10.4025/actascihumansoc.v37i1.26196.

FARO, A. J. Pequena História da Dança. Rio de Janeiro, Jorge Zahar Ed, p. 915,1998 .

FRAGA, K.; SOUZA, N. L. O caipira nas ondas do rádio: estudo de caso do 
programa Sertanejo Classe A. Rádio-Leituras, v. 7, n. 1, p. 171-188, 2016. Disponível em: <http://www.periodicos.ufop.br/pp/index.php/radioleituras/article/view/179>. Acesso em: 21 jan. 2019.

GUARATO, R. Dança e os meios de comunicação de massa. Urdimento-Revista de Estudos em Artes Cênicas, v. 2, n. 27, p. 5-20, 2016. Disponível em: http:/dx.doi.org/10.5965/1414573102272016005.

doi: $10.5965 / 1414573102272016005$.

MELO, R. A.; BARRETO, D. J. Formação em Psicologia: discursos e saberes sobre experimentações de gênero. Psicologia: ciência e profissão, p. 676-689, 2014. Disponível em: http://dx.doi.org/10.1590/1982 - 3703000932012. doi: 10.1590/1982 $-3703000932012$.

LEITAO, J. O. A relação entre caipiras e o processo de urbanização na música sertaneja entre as décadas de 1920 e 1980. Confins. Revue franco-brésilienne de géographie/Revista franco-brasilera de geografia, n. 30, p. 1-46, 2017. Disponível em: <https://journals.openedition.org/confins/11781>. Acesso em: 20 jan. 2019.

NUNES, M. L. F.; ZAMBON, R. H. É proibido cochilar: os signos e significados das práticas corporais do forró universitário como contribuição para o currículo cultural da Educação Física. Conexões, v. 16, n. 4, p. 565-581, 2018. Disponível em: http://dx.doi.org/10.20396/conex.v16i4.8652583. 10.20396/conex.v16i4.8652583.

PAES, J. M. Forró: Sociabilidade e Levante. Revista do Centro de Pesquisa Comunicação e Cultura: Barroco e Mestiçagem. ISSN 2317-3971, v. 1, n. 5, 2017.Disponível em: https://revistas.pucsp.br/algazarra/article/view/35506/24322. Acesso em: 2 fev. 2019.

PIMENTEL, C. E; GOUVEIA, V. V.; VASCONCELOS, T. C. Preferência musical, atitudes e comportamentos anti-sociais entre estudantes adolescentes: um estudo correlacional. Estudos de Psicologia, v. 22, n. 4, p. 403-413 out./dez. 2005. http://dx.doi.org/10.1590/S0103-166X2005000400008. doi: 10.1590/S0103166X2005000400008.

RODRIGUES, F. J.; SOUZA, L. Erotismo dançante e as distâncias sociais entre homens e mulheres no Brasil. Latitude, v. 11, n. 1, p. 73-120, 2017. Disponível em: https://doi.org/10.28998/2179-5428.20170103. doi: 10.28998/2179-5428.20170103.

SCHLOSSER, A.; CAMARGO, B. V.; MARCON, A. N.; MORAIS, D. X. Representações sociais de término de relacionamentos amorosos em músicas do sertanejo universitário. Psicologia em Revista, v. 22, n. 2, p. 407-427, 2016. Disponível em: http://ibict.pucminas.br/index.php/psicologiaemrevista/article/view/P.16789523.2016V22N2P407. Acesso em: 12 fev. 2019.

SILVA, L. S. Baile Funk, missão civilizatória e UPP: cultura e segurança pública na cidade do Rio de Janeiro. Brasiliana-Journal for Brazilian Studies, v. 4, n. 2, p. 
318-342, 2016. Disponível em: <https://tidsskrift.dk/bras/article/view/22261/20554>. Acesso em: 06 jan. 2019.

TOMAZZONI, A. Lições de dança na mídia. Educação. Porto Alegre, v. 38, n. 1, p. 77-86, 2015. Disponível em: http://dx.doi.org/10.15448/1981-2582.2015.1.18465. doi: 10.15448/1981-2582.2015.1.18465.

TORTOLA, E. R. C.; LARA, L. M. A dança como produto à venda em casas noturnas: um mapeamento do terreno mercadológico. Movimento, v. 17, n. 2, 2011. Disponível em: https://doi.org/10.22456/1982-8918.19999. doi: 10.22456/19828918.19999.

VIANA, L. R. O Funk no Brasil: música desintermediada na cibercultura. Sonora, v. 3, n. 5, p. 1-21. 2016. Disponível em: < https://www.publionline.iar.unicamp.br/index.php/sonora/article/view/641>. Acesso em: 10 jan. 2019.

VIEIRA, A. P.; AVELINO, D. R. Dança, música e processos criativos:possíveis interfaces. MORINGA-Artes do Espetáculo. João Pessoa, v. 5, n. 2, p. 133-152, jul./dez. $2014 . \quad$ Disponível em: <http://www.periodicos.ufpb.br/ojs/index.php/moringa/article/view/22451/12427>. Acesso em: 05 nov. 2018 